\title{
PREDICTION MODEL OF PAPER-WEB WRINKLING AND SOME NUMERICAL CALCULATION EXAMPLES WITH EXPERIMENTAL VERIFICATIONS
}

\author{
by
}

\author{
H. Hashimoto \\ Tokai University \\ JAPAN
}

\begin{abstract}
In the web handling technology, it is very important engineering problems to predict and protect web wrinkling from several view points of product quality, manufacturing cost and so on. In this paper, the prediction model for generating paperweb wrinkles due to misalignment of roller is presented with experimental verifications.
\end{abstract}

\section{NOMENCLATURE}

$a:$ web span $[\mathrm{m}]$

$B$ : web wrap angle [rad]

$E_{x}$ : Young's modulus of web in machine direction [GPa]

$E_{z}$ : Young's modulus of web in cross machine direction [GPa]

$h:$ air film thickness [m]

$k$ : web permeability $\left[\mathrm{m}^{2}\right]$

$L:$ web width $[\mathrm{m}]$

$N_{x}, N_{z}$ : normal forces [N/m]

$R$ : roller radius [m]

$T$ : web tension $[\mathrm{N} / \mathrm{m}]$

$T_{c r}$ : critical web tension to sustain wrinkle $[\mathrm{N} / \mathrm{m}]$

$\Delta T$ : work done by normal forces [Nm]

$t_{f}:$ web thickness $[\mathrm{m}]$

$U:$ total velocity $\left(=U_{r}+U_{w}\right)[\mathrm{m} / \mathrm{s}]$

$U_{r}$ : roller velocity $[\mathrm{m} / \mathrm{s}]$

$U_{w}:$ web velocity $[\mathrm{m} / \mathrm{s}]$

$\Delta U:$ strain energy $[\mathrm{Nm}]$

$x$ : coordinate in the machine direction [m]

$y:$ coordinate in the vertical direction $[\mathrm{m}]$

$z$ : coordinate in the cross machine direction [m] 
$\alpha$ : experimental constant

$\gamma_{x y}:$ strain

$\varepsilon:$ web speed parameter $(=6 \eta U / T)$

$\varepsilon_{x}, \varepsilon_{z}:$ strains

$\eta$ : air film viscosity [Pa.s]

$\kappa:$ web permeable parameter $\left(=k T B /\left(\eta t_{f} R U\right)\right)$

$\lambda:$ web width parameter $\left(=L /\left(2 R \varepsilon^{1 / 3}\right)\right)$

$\mu$ : friction coefficient

$\mu_{1}:$ local friction coefficient

$\mu_{c}:$ experimental constant

$\left.\hat{\}}_{.},\right\}_{\zeta}:$ Poisson's ratios

$\sigma:$ composite RMS roughness $\left(=\left(\sigma_{r}^{2}+\sigma_{w}^{2}\right)^{1 / 2}\right)[\mathrm{m}]$

$\sigma_{r}:$ RMS roughness of roller surface [m]

$\sigma_{w}:$ RMS roughness of web surface [m]

$\sigma_{x,} \sigma_{z}:$ normal stresses $[\mathrm{Pa}]$

$\sigma_{z c r}:$ critical buckling stress [Pa]

$\tau_{c r}:$ critical share stress $[\mathrm{Pa}]$

$\tau_{. F}:$ share stress $[\mathrm{Pa}]$

\section{INTRODUCTION}

A web is continuous flexible material such as paper, plastic film, thin metal plates etc. Before being converted to the final product, the web undergoes several processes, for example, transportation by the drag roller, press, printing, coating, drying, slittering, winding, and so on. Under such processes, the web is given the additional values to enhance the quality and function of product. However, when the web wrinkles are generated in the handling processes, the wrinkles immediately result in quality loss. Therefore, to predict and protect the wrinkles is very important engineering problems in web handling industries. Nevertheless, the literatures treating such problems are limited [1] [7].

In this paper, the theoretical modeling of paper-web wrinkling generation due to misalignment of roller is described with experimental verifications.

\section{OBSERVATION OF WRINKLES}

It is well known experimentally in the web handling industries that web wrinkles are generated due to misalignment of roller. Based on such experiences, several investigators successfully formulated the prediction model of wrinkles for uniform webs with constant Young's modulus in machine and cross machine directions. However, some materials such as paper and some optical films used for the Liquid Crystal Display (LCD) have different Young's modulus in machine and cross machine directions. Moreover, in the case of paper-webs, the web permeability may significantly affect the generation of wrinkles. In this paper, at the first step of theoretical modeling, the wrinkles generated in two kinds of paper-web are observed under various operation conditions.

\section{Test rig for observation of paper-web wrinkles}

Figure 1 shows the test rig for observing the generation of web wrinkles. The tram error (skew angle) is changed continuously by the skew angle control roller(3), which is 


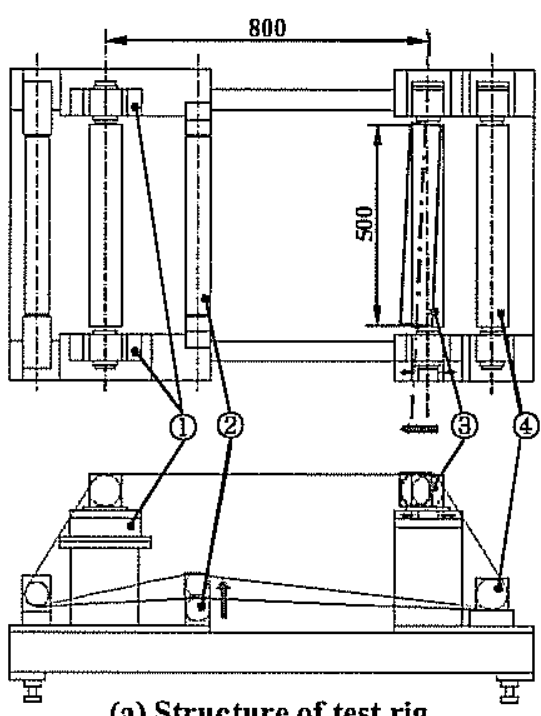

(a) Structure of test rig

(b) Detail of skew control mechanism

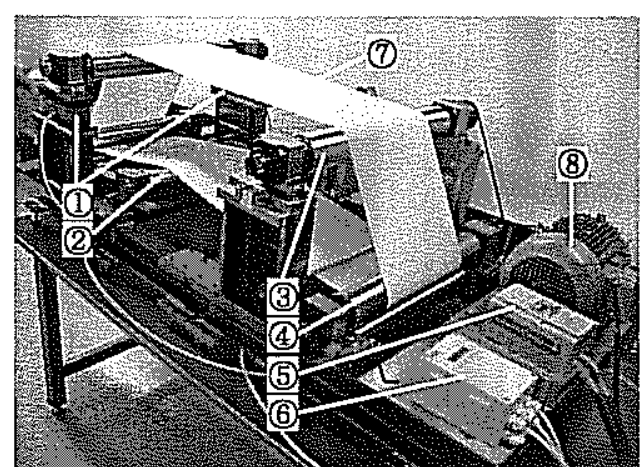

(c) Overview of test rig

\begin{tabular}{|l|l|}
\hline & \multicolumn{1}{|c|}{ Name of parts } \\
\hline (1) & Load cell \\
\hline (2) & Tension control roller( $\mathrm{R}=\mathbf{0 . 0 3}[\mathrm{m}])$ \\
\hline (3) & Skew angle control roller $(\mathrm{R}=0.04[\mathrm{~m}])$ \\
\hline (4) & Rotating roller \\
\hline (5) & Speed controller \\
\hline 66 & Tension unit \\
\hline 77 & Web \\
\hline 8 & Driving motor \\
\hline
\end{tabular}

Figure 1 - Test rig for observation of web wrinkle

supported by the pivot at one end of the roller, from $0 \mathrm{deg}$ to $1.5 \mathrm{deg}$ with micro-screw. The accuracy of setting the angle is less than $0.01 \mathrm{deg}$. The endless type web(7) is supported by five rollers. The web tension is applied by the tension control roller(2), and the magnitude of web tension is measured by the load cell(1) and displayed on the tension unit(6). The rotating roller(4) is driven by the driving motor(8) though velt.

Two kinds of paper, uncoated paper(newsprint) and coated paper, were used as test webs. Figure 2 shows the microscopic image of surface topography of these two kinds of paper-webs. The physical properties of webs are listed in Table 1.

A procedure for the observation of wrinkles is to fix step by step the web tension for a given velocity and to increase slowly the misalignment of roller with micro-screw until the web wrinkle is generated. The critical skew angle for generating wrinkle is read through the pitch of micro-screw rotation, and the web wrinkle is recorded by the videorecorder at the same time. The test conditions are listed in Table 2. 


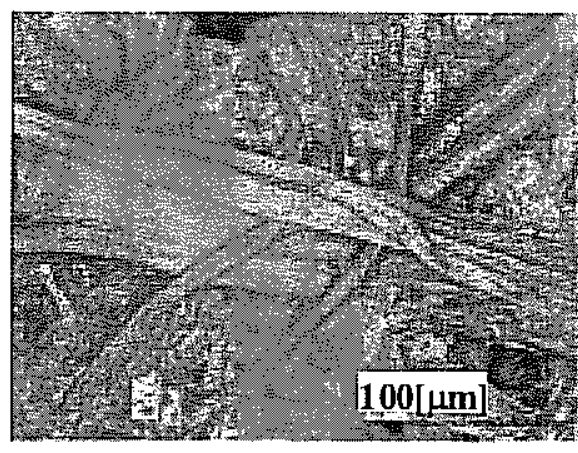

(a) Newspaper

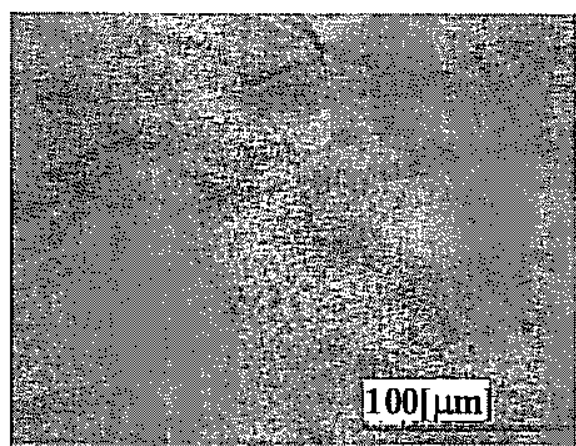

(b) Coated paper

Figure 2-Microscopic image of surface structure

Table.1 Physical properties of test webs

\begin{tabular}{|c|c|c|c|}
\hline Item & Web & Newsprint & Coated paper \\
\hline RMS roughness & $\sigma_{w}[\mu \mathbf{m}]$ & 4.0 & 2.0 \\
\hline Permeability & $\mathbf{k}\left[\mathrm{m}^{2}\right]$ & $4.03 \times 10^{-15}$ & $5.52 \times 10^{-17}$ \\
\hline Thickness & $\mathbf{t}_{\mathbf{f}}[\mu \mathbf{m}]$ & 66.5 & 48.2 \\
\hline $\begin{array}{l}\text { Young's modulus in } \\
\text { machine direction }\end{array}$ & ${ }^{n} E_{x}[\mathbf{G P a}]$ & 4.66 & 8.89 \\
\hline $\begin{array}{l}\text { Young's modulus in } \\
\text { cross direction }\end{array}$ & ${ }^{n} E_{z}[\mathrm{GPa}]$ & 1.66 & 2.73 \\
\hline
\end{tabular}

Table.2 Test conditions

\begin{tabular}{|lr|c|}
\hline \multicolumn{2}{|c|}{ Item } & Measured value \\
\hline Span & $\mathbf{a}[\mathrm{m}]$ & $\mathbf{0 . 8}$ \\
\hline Roller radius & $\mathbf{R}[\mathrm{m}]$ & $\mathbf{0 . 0 4}$ \\
\hline Web wrap angle & $\mathbf{B}[\mathrm{deg}]$ & $\mathbf{6 0}$ \\
\hline Web velocity & $\mathrm{U}[\mathrm{m} / \mathrm{s}]$ & $\mathbf{1 , 5}$ \\
\hline Web tension & $\mathrm{T}[\mathrm{N} / \mathrm{m}]$ & $\mathbf{0} \sim \mathbf{3 5 0}$ \\
\hline Tram error & $\theta[\mathrm{deg}]$ & $\mathbf{0 \sim 0 . 2 5}$ \\
\hline
\end{tabular}




\section{Test results}

Figure 3 shows the generation of wrinkles under transportation with the velocity of $U$ $=1[\mathrm{~m} / \mathrm{s}]$ for the coated paper-web. For the case of non misalignment, there is no wrinkle as shown in Figure 3(i). As the tram error of roller increases slowly, the ripples can be seen on the web surface as shown in Figure 3(ii), and when the skew angle reaches to the critical angle the ripples disappear and the generation of wrinkle is observed on the center line of the web at the point just before entering the misaligned roller as shown in Figure 3(iii). After the onset of wrinkle, it is sustained and transported around the misaligned roller as shown in Figure 3(iv).

Figure 4 shows the trough generation with slope against the center line of the web. Such kind of wrinkle results in quality loss of the web, so it is very important to predict and prevent the generation of trough for given operation conditions of web handling system.

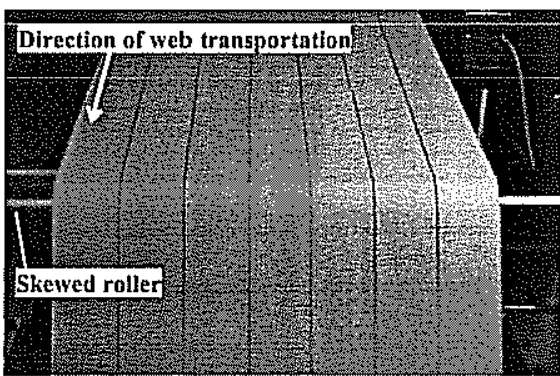

(i)

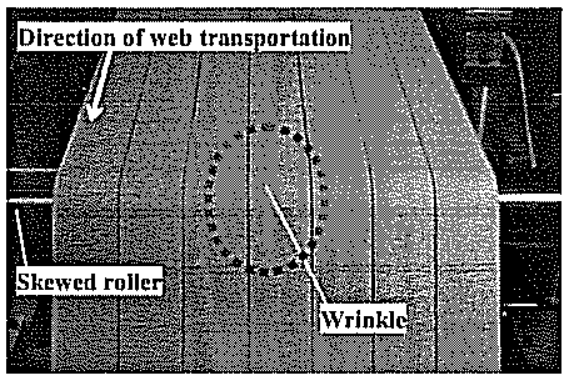

(ii)

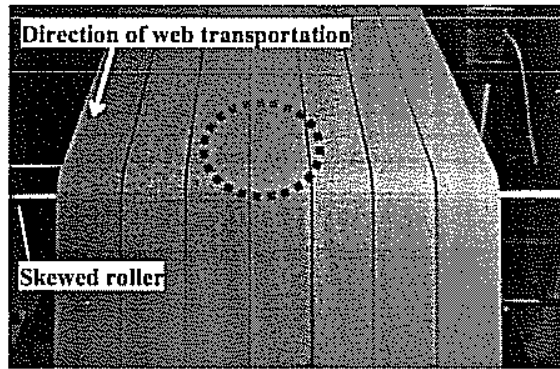

(ii)

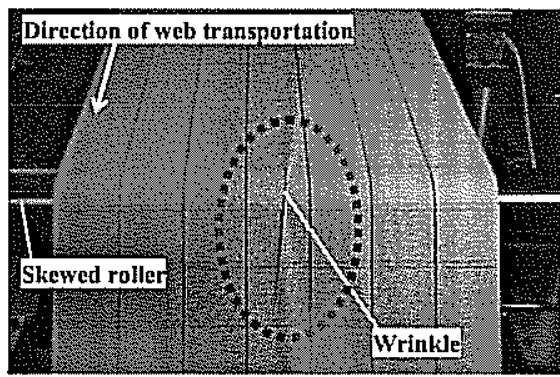

(v)

Figure 3 - Observation of generation of wrinkles in transporting web ( $\mathrm{U}=1[\mathrm{~m} / \mathrm{s}]$,Coated paper) 


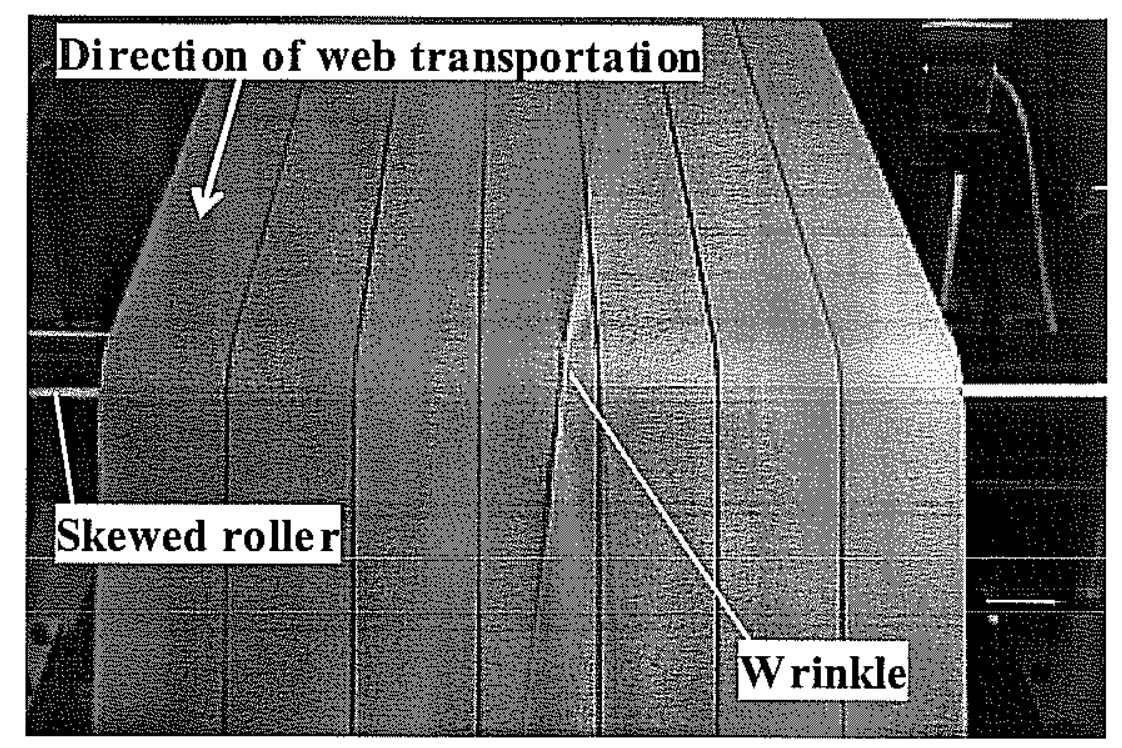

(a) Front view

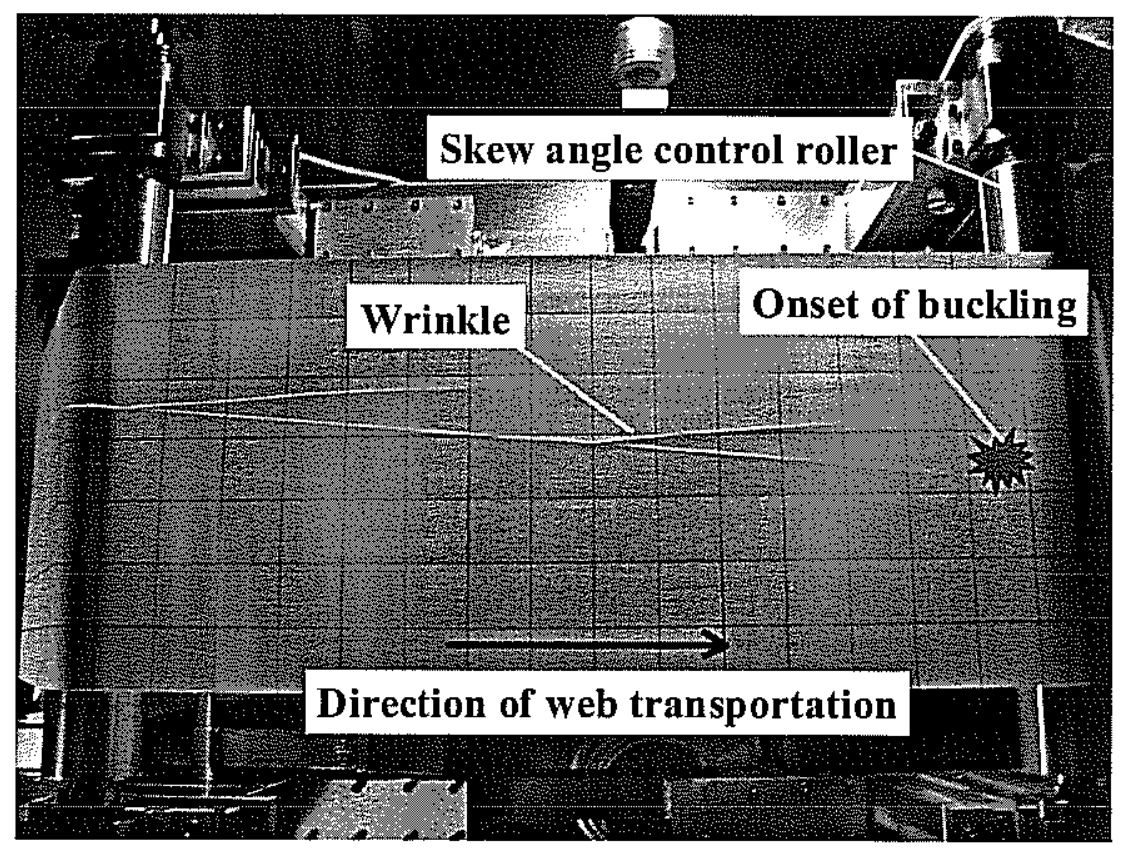

\section{(b) Upper view}

Figure 4-Observation of generation of wrinkles in transporting web

$(\mathrm{U}=1[\mathrm{~m} / \mathrm{s}]$, Coated paper) 
Figure 5 and 6 show the variation of critical skew angle with the web tension. In the case of the uncoated paper(newsprint), the critical skew angles exist along "L-shaped line" consisting of the curved line(1) and the vertical straight line(2). There was no wrinkle below the curved line(1) and left to the vertical straight line(2). For both cases of $U=1[\mathrm{~m} / \mathrm{s}]$ and $5[\mathrm{~m} / \mathrm{s}]$, there is no essential difference between the results. Therefore, it is considered that the velocity $U$ does not affect the critical skew angles.

The similar type of "L-shaped line" of critical skew angles was observed in the case of the coated paper, as shown in Figure 6. However, in this case, the vertical line for $U$ $=5[\mathrm{~m} / \mathrm{s}]$ shifts to the right against the line for $U=1[\mathrm{~m} / \mathrm{s}]$, and it is considered that the velocity significantly affect the critical skew angles.

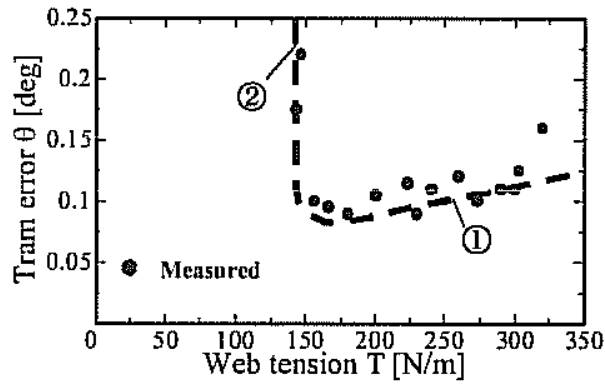

(a) $\mathrm{U}=1[\mathrm{~m} / \mathrm{s}]$

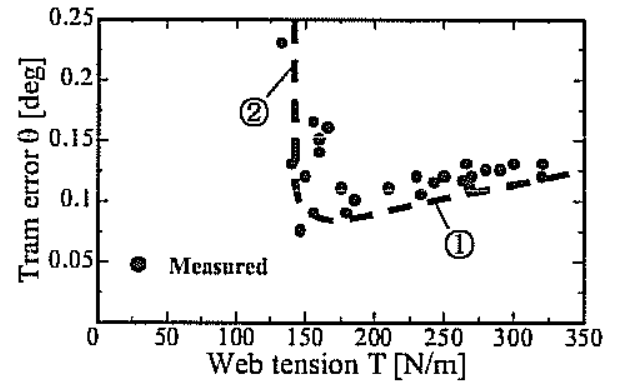

(b) $\mathrm{U}=5[\mathrm{~m} / \mathrm{s}]$

Figure 5 - Example of experimental results for newsprint

$(\mathrm{R}=0.04[\mathrm{~m}], \mathrm{a}=0.8[\mathrm{~m}], \mathrm{B}=60[\mathrm{deg}], \mathrm{L}=0.3[\mathrm{~m}])$

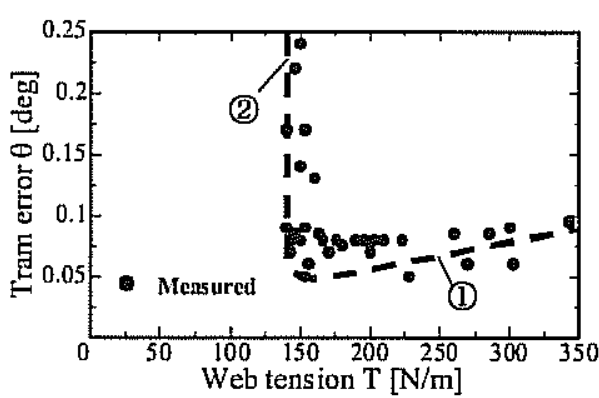

(a) $\mathrm{U}=1[\mathrm{~m} / \mathrm{s}]$

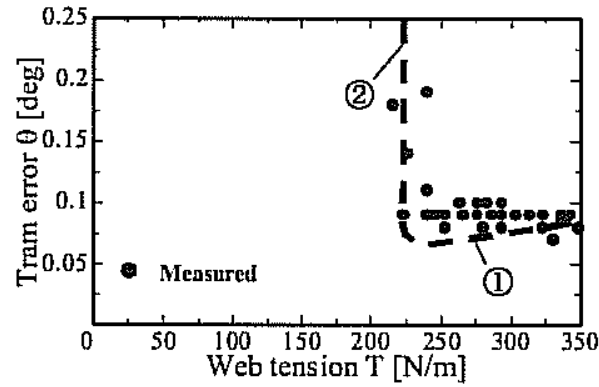

(b) $\mathrm{U}=5[\mathrm{~m} / \mathrm{s}]$

Figure 6 - Example of experimental results for coated paper

$(\mathrm{R}=0.04[\mathrm{~m}], \mathrm{a}=0.8[\mathrm{~m}], \mathrm{B}=60[\mathrm{deg}], \mathrm{L}=0.3[\mathrm{~m}])$

\section{THEORETICAL PREDICTION MODEL}

\section{Theoretical prediction model for curved line(1)}

As has been done in Ref. [6], the curved line(1) independent of the velocity will be determined based on the classic buckling theory. The energy method is applied to find the critical buckling load of nonuniform web with different Young's modulus in the machine and cross machine directions as shown in Figure 7. In this method, the strain energy in buckling, $\Delta U$, is set equal to the work done by the forces, $\Delta T$, as: 


$$
\Delta \mathrm{U}=\Delta \mathrm{T}
$$

where $\Delta U$ and $\Delta T$ are given respectively as:

$$
\begin{aligned}
& \Delta \mathrm{U}=\frac{1}{2} \iiint_{\mathrm{V}}\left(\sigma_{\mathrm{x}} \varepsilon_{\mathrm{x}}+\sigma_{\mathrm{z}} \varepsilon_{\mathrm{z}}+\tau_{\mathrm{xz}} \gamma_{\mathrm{xz}}\right) \mathrm{dxdydz} \\
& \Delta \mathrm{T}=\frac{1}{2} \iint_{\mathrm{A}}\left\{\mathrm{N}_{\mathrm{x}}\left(\frac{\partial \mathrm{v}}{\partial \mathrm{x}}\right)^{2}+\mathrm{N}_{\mathrm{z}}\left(\frac{\partial \mathrm{v}}{\partial \mathrm{z}}\right)^{2}\right\} \mathrm{dxdz}
\end{aligned}
$$

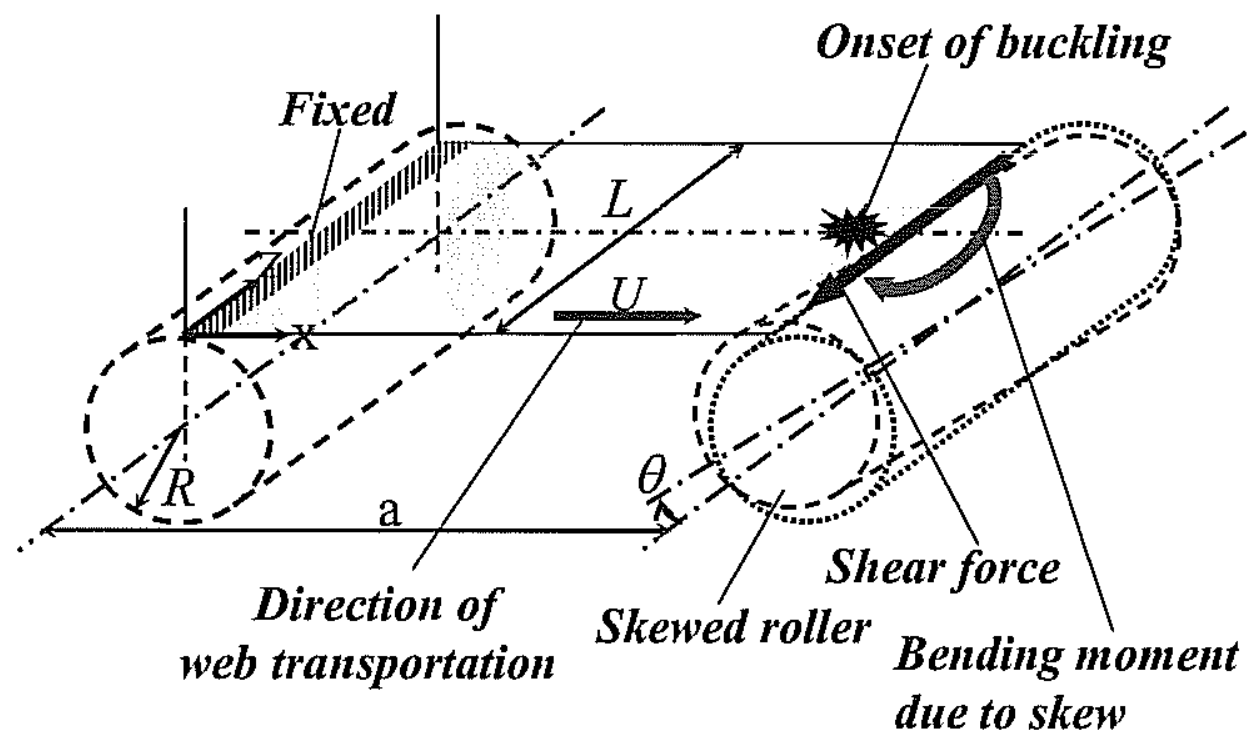

Figure 7- Buckling generation by shear force due to roller misalignment

From Fooke's law,

$$
\left.\begin{array}{l}
\varepsilon_{\mathrm{x}}=\frac{\sigma_{\mathrm{x}}}{\mathrm{E}_{\mathrm{x}}}-y_{\mathrm{z}} \frac{\sigma_{\mathrm{z}}}{\mathrm{E}_{\mathrm{z}}} \\
\varepsilon_{\mathrm{z}}=\frac{\sigma_{\mathrm{z}}}{\mathrm{E}_{\mathrm{z}}}-\nu_{\mathrm{x}} \frac{\sigma_{\mathrm{x}}}{\mathrm{E}_{\mathrm{x}}} \\
\tau_{\mathrm{xz}}=\mathrm{G}_{\mathrm{xz}} \gamma_{\mathrm{xz}}
\end{array}\right\}
$$

and from the relation between the strain and displacement:

$$
\varepsilon_{\mathrm{x}}=-\mathrm{y} \frac{\partial^{2} v}{\partial \mathrm{x}^{2}}, \varepsilon_{\mathrm{z}}=-\mathrm{y} \frac{\partial^{2} v}{\partial \mathrm{z}^{2}}, \gamma_{\mathrm{xz}}=-2 \mathrm{y} \frac{\partial^{2} v}{\partial \mathrm{x} \partial \mathrm{z}}
$$


Using Eqs.(3) and (4), Eq.(1) is rewritten as:

$$
\begin{aligned}
\Delta \mathrm{U}= & \frac{1}{2} \iint_{A}\left\{\mathrm{D}_{\mathrm{xx}}\left(\frac{\partial^{2} v}{\partial \mathrm{x}^{2}}\right)^{2}+\mathrm{D}_{\mathrm{zz}}\left(\frac{\partial^{2} v}{\partial \mathrm{z}^{2}}\right)^{2}\right. \\
& \left.+\left(y_{\mathrm{x}} \mathrm{D}_{\mathrm{zz}}+y_{\mathrm{z}} \mathrm{D}_{\mathrm{xx}}\right) \frac{\partial^{2} v}{\partial \mathrm{x}^{2}} \frac{\partial^{2} v}{\partial \mathrm{z}^{2}}+\frac{\mathrm{G}_{\mathrm{xz}} \mathrm{t}_{\mathrm{f}}{ }^{3}}{3}\left(\frac{\partial^{2} v}{\partial \mathrm{x} \partial \mathrm{z}}\right)^{2}\right\} \mathrm{dxdz}
\end{aligned}
$$

where:

$$
D_{x x}=\frac{E_{x} t_{f}^{3}}{12\left(1-\nu_{x} \nu_{z}\right)}, D_{z z}=\frac{E_{z} t_{f}^{3}}{12\left(1-p_{x} p_{z}\right)}
$$

The displacement in $y$-direction, $v$, is assumed as:

$$
v=\sum_{\mathrm{m}=1 \mathrm{n}=1}^{\infty} \sum_{\mathrm{mm}}^{\infty} \sin \frac{\mathrm{m} \pi \mathrm{x}}{\mathrm{a}} \sin \frac{\mathrm{n} \pi \mathrm{z}}{\mathrm{L}}
$$

Substituting Eqs. (2), (5) and (7) into Eq. (1), the following relation is finally obtained.

$$
\sigma_{\mathrm{x}} \mathrm{m}^{2}+\sigma_{\mathrm{z}} \mathrm{m}^{2} \frac{\mathrm{a}^{2}}{\mathrm{~L}^{2}}=\sigma_{\mathrm{e}}\left(\mathrm{m}^{4}+\zeta_{1} \mathrm{n}^{4} \frac{\mathrm{a}^{4}}{\mathrm{~L}^{4}}+\zeta_{2} \mathrm{~m}^{2} \mathrm{n}^{2} \frac{\mathrm{a}^{2}}{\mathrm{~L}^{2}}\right)
$$

where:

$$
\left.\begin{array}{l}
\zeta_{1}=\frac{\mathrm{E}_{\mathrm{z}}}{\mathrm{E}_{\mathrm{x}}}, \zeta_{2}=\frac{4\left(1-p_{\mathrm{x}} p_{\mathrm{z}}\right) \mathrm{E}_{\mathrm{z}}}{1+p_{\mathrm{x}}+\left(1+p_{\mathrm{x}}\right) / \zeta_{\mathrm{l}}}+\nu_{\mathrm{z}}+\nu_{\mathrm{x}} \zeta_{\mathrm{f}} \\
\sigma_{\mathrm{x}}=\frac{\mathrm{N}_{\mathrm{x}}}{\mathrm{t}_{\mathrm{f}}}, \sigma_{\mathrm{z}}=\frac{\mathrm{N}_{\mathrm{z}}}{\mathrm{t}_{\mathrm{f}}}, \sigma_{\mathrm{e}}=\frac{\pi^{2} \mathrm{D}_{\mathrm{xx}}}{\mathrm{a}^{2} \mathrm{t}_{\mathrm{f}}}
\end{array}\right\}
$$

Applying the same manner as used in Ref. [6], the critical normal stress necessary to generate wrinkles for nonuniform webs, $\sigma_{\mathrm{zer}}$, is obtained as follows:

$$
\sigma_{\mathrm{zer}}=\frac{\mathrm{L}^{2}}{\mathrm{i}^{2} \mathrm{a}^{2}}\left\{\sigma_{\mathrm{e}}\left(1+\zeta_{1} \mathrm{i}^{4} \frac{\mathrm{a}^{4}}{\mathrm{~L}^{4}}+\zeta_{2} \mathrm{i}^{2} \frac{\mathrm{a}^{2}}{\mathrm{~L}^{2}}\right)-\sigma_{\mathrm{x}}\right\}
$$

where the integer $i$ is determined by the following relation:

$$
\sigma_{\mathrm{e}}\left\{1-\mathrm{i}^{2}(\mathrm{i}+1)^{2} \zeta_{1} \frac{\mathrm{a}^{4}}{\mathrm{~L}^{4}}\right\}<\sigma_{\mathrm{x}}<\sigma_{\mathrm{e}}\left\{1-(\mathrm{i}-1)^{2} \mathrm{i}^{2} \zeta_{1} \frac{\mathrm{a}^{4}}{\mathrm{~L}^{4}}\right\}
$$


The critical share stress, $\tau_{\mathrm{cr}}$, is then given as:

$$
\tau_{\mathrm{cr}}=\sqrt{\sigma_{\mathrm{zcr}}^{2}-\sigma_{\mathrm{x}} \sigma_{\mathrm{zcr}}}
$$

On the other hand, the displacement of nonuniform webs due to shear force $F$ acting on the misaligned roller as shown in Figure 7 is given as follows:

$$
\mathrm{W}=\frac{\nu_{\mathrm{x}} \mathrm{F}}{2 \mathrm{E}_{\mathrm{x}} \mathrm{I}} \mathrm{xz}^{2}+\frac{\mathrm{F}}{6 \mathrm{E}_{\mathrm{x}} \mathrm{I}} \mathrm{x}^{2}-\frac{\nu_{\mathrm{x}} \mathrm{FL}^{2}}{8 \mathrm{E}_{\mathrm{x}} \mathrm{I}}
$$

From Eq.(13), the deflection angle at the end of the web, $x=a$ and $z=L / 2$, is obtained as:

$$
\theta=\left(\frac{\partial w_{z=L / 2}}{\partial x}\right)_{x=a}=\frac{F_{a} 2}{2 F_{x} I}
$$

where $F$ and $I$ are respectively expressed as:

$$
\mathrm{F}=\mathrm{Lt}_{\mathrm{f}} \tau_{\mathrm{cr}}, \mathrm{I}=\frac{\mathrm{L}^{3} \mathrm{t}_{\mathrm{f}}}{12}
$$

From Eqs. (14) and (15), the condition for generating wrinkles is given as:

$$
\theta \geq \theta_{\mathrm{cr}}=\frac{6 \mathrm{a}^{2} \tau_{\mathrm{cr}}}{\mathrm{E}_{\mathrm{x}}^{2} \mathrm{~L}^{2}}
$$

where $\theta_{c r}$ is the critical skew angle of misaligned roller and the critical shear stress $\tau_{c r}$ is given by Eq. (12).

Figure 8 shows the applicability of Eq. (16) for predicting the critical skew angle $\theta_{c r}$ indicated by the curved line(1) in Figure 6 . As can be seen in Figure 8, there are good agreements between the predicted results and the measured data. 


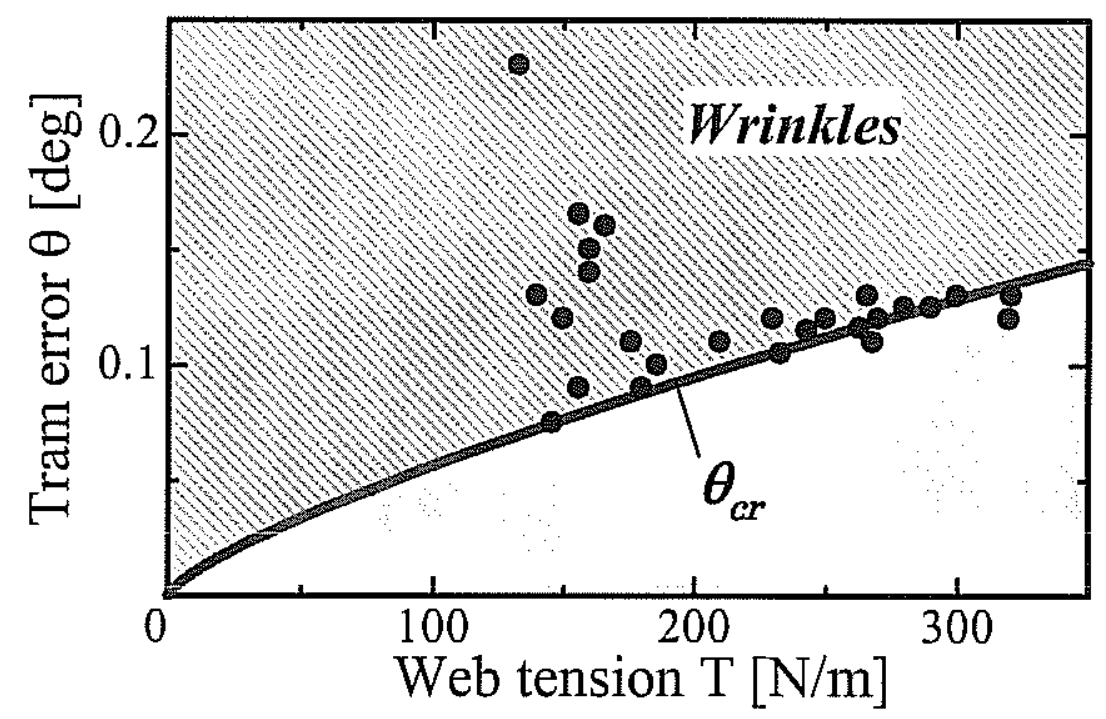

Figure8 - Predicted result of curved line (1)

(nesprint, $\mathrm{U}=5[\mathrm{~m} / \mathrm{s}]$ )

\section{Theoretical prediction model for vertical straight line(2)}

As pointed out in Ref. [6], much higher cross machine direction stresses are needed to wrinkle a web in the form of a shell than in the form of a plane, thus the wrinkles generated can be transported around the surface of the misaligned roller, as shown in Figure 9, only when there are inadequate traction between the paper-web and roller to sustain the wrinkle. 


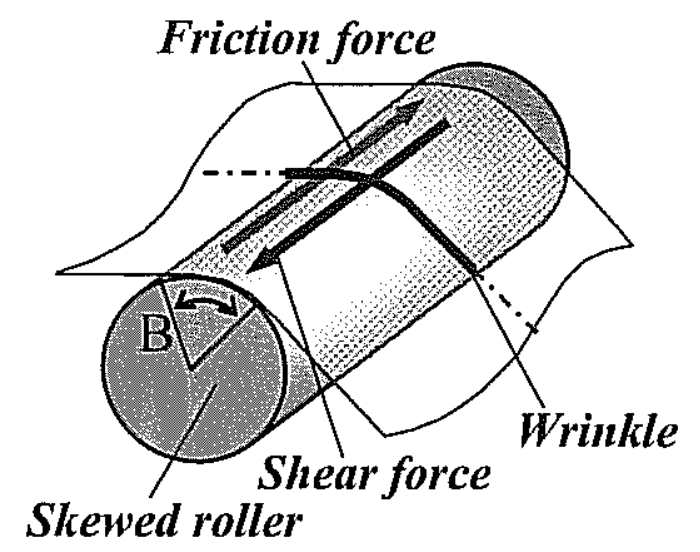

Figure $9-$ Web buckling sustained by friction force between web and roller

The energy method is also used to determine the buckling stress of nonuniform web in the form of a shell as follows.

The strain energy $\Delta U$ is given by :

$$
\begin{aligned}
\Delta \mathrm{U}= & \left.\frac{\mathrm{t}_{\mathrm{f}}}{2\left(1-y_{\mathrm{x}} y_{\mathrm{z}}\right)} \iint_{\mathrm{A}}\left(\mathrm{E}_{\mathrm{x}} \varepsilon_{1}{ }^{2}+\mathrm{E}_{\mathrm{z}} \varepsilon_{\mathrm{z}}{ }^{2}\right)+\left(\mathrm{E}_{\mathrm{x}} y_{\mathrm{z}}+\mathrm{E}_{\mathrm{z}} p_{\mathrm{x}}\right) \varepsilon_{1} \varepsilon_{2}\right) \mathrm{dxdz} \\
& +\frac{\mathrm{D}_{\mathrm{xx}}}{2} \iint_{\mathcal{A}}\left(\frac{\partial^{2} v}{\partial \mathrm{z}^{2}}\right)^{2} \mathrm{dxdz}
\end{aligned}
$$

Assuming the displacement $\mathrm{v}$ as the following form:

$$
v=-\sum_{m=I}^{\infty} \mathrm{A} \sin \frac{\mathrm{m} \pi \mathrm{z}}{\mathrm{L}}
$$

the strains $\varepsilon_{1}$ and $\varepsilon_{2}$ are respectively given as:

$$
\varepsilon_{1}=\varepsilon_{0}-\nu_{x} \sum_{m=1}^{\infty} \frac{A_{m}}{R} \sin \frac{m \pi z}{L}, \varepsilon_{2}=-\nu_{x} \varepsilon_{0}-\sum_{m=1}^{\infty} \frac{A_{m}}{R} \sin \frac{m \pi z}{L}
$$

where:

$$
\varepsilon_{0}=-\frac{N_{z}}{E_{z} t_{f}}
$$

Substituting Eqs. (18) $\square(20)$ into Eq. (17), the strain energy $\Delta U$ is expressed as: 


$$
\begin{aligned}
\Delta \mathrm{U}= & -\pi \mathrm{t}_{\mathrm{f}}\left(\mathrm{E}_{\mathrm{x}} \nu_{\mathrm{z}}+\mathrm{E}_{\mathrm{z}} y_{\mathrm{x}}\right) \varepsilon_{0} \int_{0}^{\mathrm{L}} \sum_{\mathrm{m}=1}^{\infty} \mathrm{A}_{\mathrm{m}} \sin \frac{\mathrm{m} \pi \mathrm{z}}{\mathrm{L}} \mathrm{dx} \\
& +\sum_{\mathrm{m}=1}^{\infty} \mathrm{A}_{\mathrm{m}}{ }^{2} \frac{\pi \mathrm{L} \mathrm{t}_{\mathrm{f}} \mathrm{E}_{\mathrm{x}}}{2 \mathrm{R}}+\sum_{\mathrm{m}=1}^{\infty} \mathrm{A}_{\mathrm{m}}{ }^{2} \frac{\mathrm{m}^{4} \pi^{4}}{2 \mathrm{~L}^{4}} \pi \mathrm{RLD}_{\mathrm{zz}}
\end{aligned}
$$

On the other hand, the work done by the compressible force $N_{z}$ is:

$$
\Delta \mathrm{T}=2 \pi \mathrm{N}_{\mathrm{z}} \nu_{x} \int_{0}^{\mathrm{L}} \sum_{\mathrm{m}=1}^{\infty} \mathrm{A}_{\mathrm{m}} \sin \frac{\mathrm{m} \pi \mathrm{z}}{\mathrm{L}} \mathrm{dz}+\sum_{\mathrm{m}=1}^{\infty} \mathrm{A}_{\mathrm{m}}{ }^{2} \frac{\mathrm{m}^{2} \pi^{2}}{2 \mathrm{~L}^{2}} \mathrm{~N}_{\mathrm{z}} \pi \mathrm{RL}
$$

Equating Eq. (21) and (22), the critical compressible force $N_{z c r}$ is obtained as:

$$
\mathrm{N}_{z c r}=\frac{\mathrm{m}^{2} \pi^{2}}{\mathrm{~L}^{2}} \mathrm{D}_{z z}+\frac{\mathrm{t}_{\mathrm{f}} \mathrm{E}_{\mathrm{x}}}{\mathrm{R}^{2}} \frac{\mathrm{L}^{2}}{\mathrm{~m}^{2} \pi^{2}}
$$

Thus, the critical buckling stress of nonuniform webs in the form of a shell, $\sigma_{z c r}$ is given as:

$$
\sigma_{z c r}=\frac{N_{z c r}}{t_{f}}=\frac{D_{z z}}{t_{f}} \frac{m^{2} \pi^{2}}{L^{2}}+\frac{E_{x}}{R^{2}} \frac{L^{2}}{m^{2} \pi^{2}}
$$

The minimum value of $\sigma_{z c r}$ is then given as:

$$
\sigma_{\mathrm{zcr}}=2 \sqrt{\frac{\mathrm{D}_{\mathrm{zz}}}{\mathrm{t}_{\mathrm{f}}} \frac{\mathrm{E}_{\mathrm{x}}}{\mathrm{R}^{2}}}=\frac{\mathrm{t}_{\mathrm{f}}}{\mathrm{R}} \sqrt{\frac{\mathrm{E}_{\mathrm{x}} \mathrm{E}_{\mathrm{z}}}{3\left(1-\nu_{\mathrm{x}} y_{\mathrm{z}}\right)}}
$$

The maximum compressible stress supported by friction force is:

$$
\sigma_{z \max }=\left(\sigma_{z}\right)_{z=L / 2}=\mu \frac{T}{2 R} \frac{L}{t_{f}}
$$

From Eq. (25) and (26), the condition for sustaining the wrinkles over the surface of misaligned roller is given as:

$$
\mathrm{T}>\mathrm{T}_{\mathrm{cr}}=\frac{2 t_{\mathrm{f}}^{2}}{\mu \mathrm{L}} \sqrt{\frac{\mathrm{E}_{\mathrm{x}} \mathrm{E}_{z}}{3\left(1-\nu_{\mathrm{x}} \nu_{z}\right)}}
$$

Figure 10 shows the measured data of friction coefficient between two kinds of paper-webs, coated paper-web and uncoated paper-web (newsprint), and steel roller for a wide range of velocity. As can be seen in the figure, the friction coefficient strongly depends on the magnitude of web tension and velocity. Especially, in the case of coated paper-web, the friction force decreases significantly with an increase of velocity. The friction coefficient between the paper-web and steel roller was successfully predicted based on the contact mechanics which was formulated by Hashimoto [8]. But, in this paper, the following more simple empirical model, which shows the good agreements to the measured data, is used [9]. 


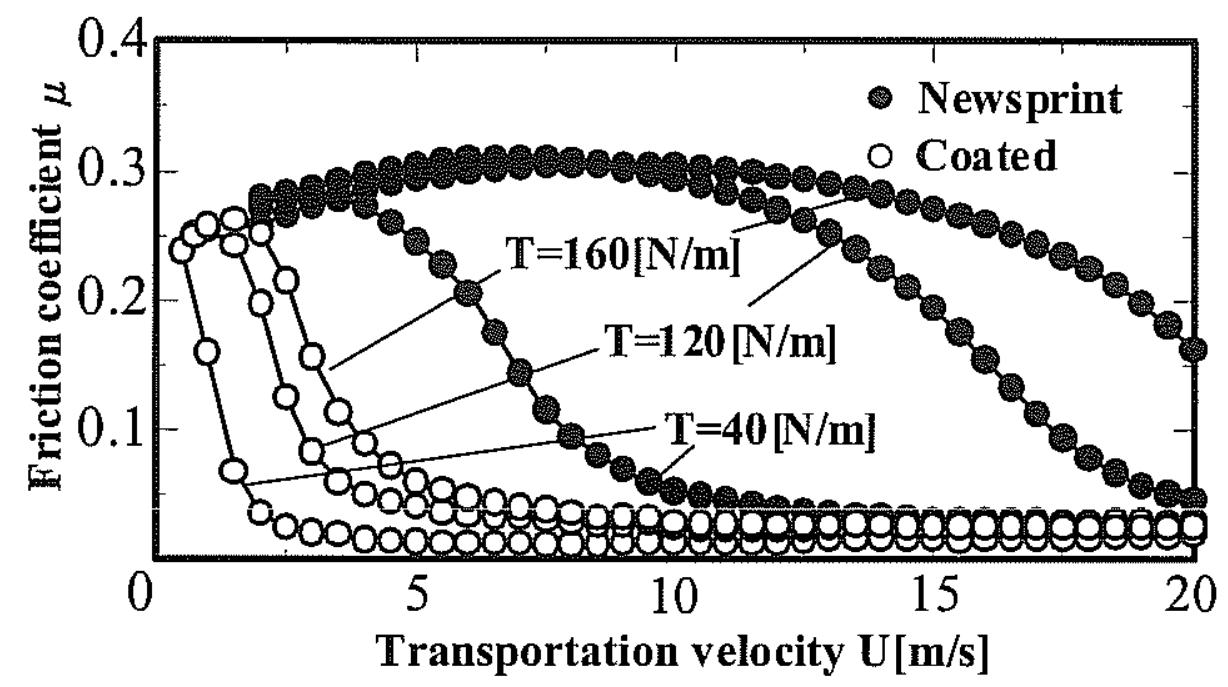

Figure 10 - Variation of friction coefficient with velocity as a parameter of web tension $(\mathrm{R}=0.055[\mathrm{~m}], \mathrm{B}=60[\mathrm{deg}], \mathrm{L}=0.035[\mathrm{~m}])$

$$
\mu=\frac{1}{\mathrm{RB}} \int_{\mathrm{RB} / 2}^{\mathrm{RB}} \mu_{\mathrm{l}} \mathrm{dx}
$$

where:

$$
\mu_{\mathrm{l}}=\left\{\begin{array}{lc}
\mu_{\mathrm{c}} & (\mathrm{h}<\alpha \sigma) \\
\frac{\mu_{\mathrm{c}}}{3-\alpha}\left(3-\frac{\mathrm{h}}{\sigma}\right)+\frac{\eta \mathrm{RU}}{\mathrm{hT}} & (\alpha \sigma \leq \mathrm{h} \leq 3 \sigma) \\
\frac{\eta \mathrm{RU}}{\mathrm{hT}} & (\mathrm{h}>3 \alpha)
\end{array}\right.
$$

where $\mathrm{U}=\mathrm{U}_{\mathrm{r}}+\mathrm{U}_{\mathrm{w}}, \sigma=\left(\sigma_{\mathrm{w}}{ }^{2}+\sigma_{\mathrm{r}}{ }^{2}\right)^{1 / 2}$, and $\alpha$ and $\mu_{\mathrm{c}}$ are determined experimentally. In this case $\alpha=2$ and $\mu_{\mathrm{c}}=0.3$ were used for the prediction of friction coefficient for the coated and uncoated paper-webs.

To determine the air film thickness between the paper-web and steel roller, the following formula derived by Hashimoto [10] is applied.

$$
\mathrm{h}=\mathrm{R} \varepsilon^{2 / 3}\left(0.589-1.614 \frac{1}{\lambda}+1.764 \frac{1}{\lambda^{2}}\right)-\mathrm{R} \kappa\left(1+\frac{2 \mathrm{x}}{\mathrm{RB}}\right)
$$

where: 


$$
\lambda=\frac{\mathrm{L}}{2 \mathrm{R} \varepsilon^{1 / 3}}, \varepsilon=\frac{6 \eta \mathrm{U}}{\mathrm{T}}, \kappa=\frac{\mathrm{kTB}}{\eta \mathrm{t}_{\mathrm{f}} \mathrm{RU}}
$$

Figure 11 shows the applicability of Eq. (27) for predicting the critical skew angle $\theta_{c r}$ indicated by the vertical straight line(2) in Figure 6. As can be seen in Figure 11, there are good agreements between the predicted results and the measured data.

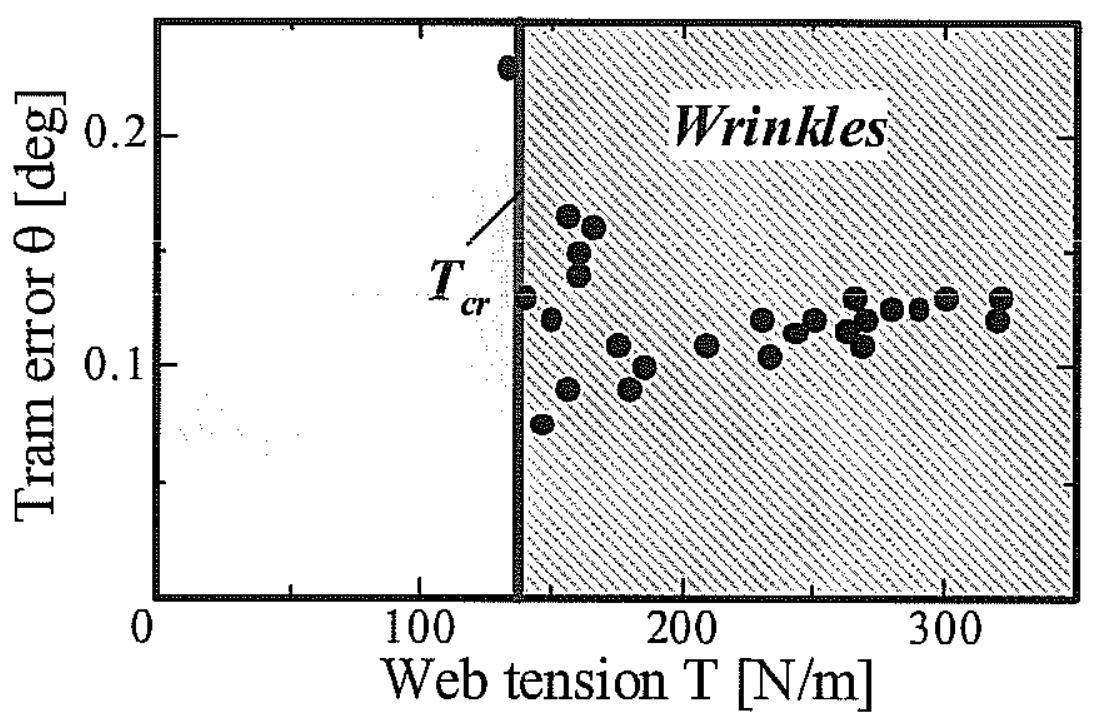

Figure 11 - Predicted result for vertical straight line (2) (newspring, $\mathrm{U}=5[\mathrm{~m} / \mathrm{s}]$ )

\section{RESULTS AND DISCUSSIONS}

The predicted results based on the present theoretical model are compared with the measured data for various conditions in Figs. 12 and 13.

Figure 12(i) shows the results for newsprint by changing the web width for the velocity of $U=1[\mathrm{~m} / \mathrm{s}]$. The critical skew angle $\theta_{c r}$ and the critical web tension $T_{c r}$ are decreased with an increase of web width, and then the web wrinkling region becomes larger.

Figure 12(ii) shows the results for the velocity of $U=5[\mathrm{~m} / \mathrm{s}]$. The web permeability of newsprint decreases drastically the air film thickness between the web and roller. Then, the friction coefficient keeps constant value for a wide range of velocity. As a result, the velocity does not significantly affect the web wrinkle generation as shown in the figures. As can be seen in the figures, the predicted results agree well with the measured data for various conditions.

Figure 13(i) shows the results for coated paper by changing the web width for the velocity of $U=1[\mathrm{~m} / \mathrm{s}]$, and Figure13(ii) shows the results for $U=5[\mathrm{~m} / \mathrm{s}]$, respectively. In both cases, the critical skew angle $\theta_{c r}$ and the critical web tension $T_{c r}$ are decreased with an increase of web width, and then the web wrinkling region becomes larger. The air film thickness between the coated paper and roller increases considerably with an 
increase of velocity because of very low permeability of coated paper, thus the friction coefficient decreases significantly. As a result, the critical tension to sustain the wrinkle on the misaligned roller surface, $T_{c r}$, becomes larger, and then the web wrinkling region for the coated paper web becomes smaller with an increase of the velocity. Good agreements can be seen the predicted results and the measured data for various conditions.
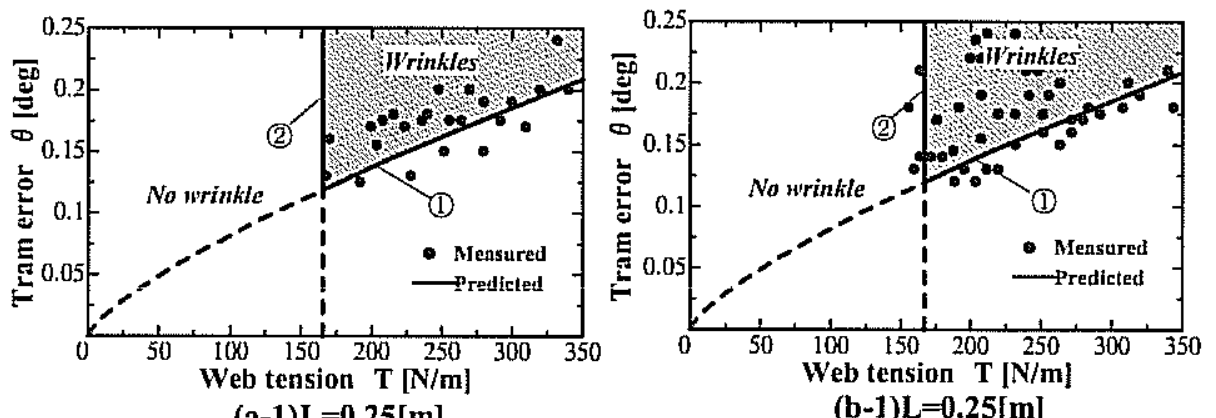

$(\mathrm{a}-1) \mathrm{L}=0.25[\mathrm{~m}]$
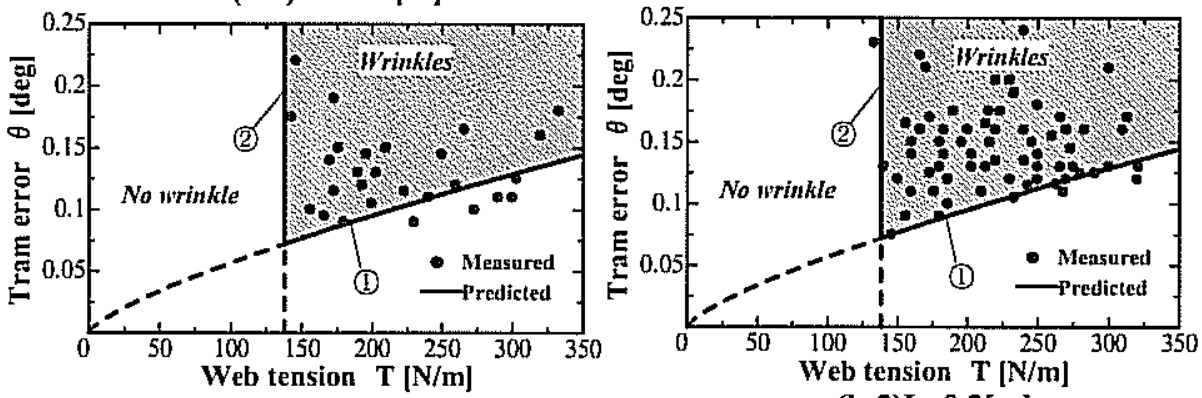

$(\mathrm{a}-2) \mathrm{L}=0.3[\mathrm{~m}]$

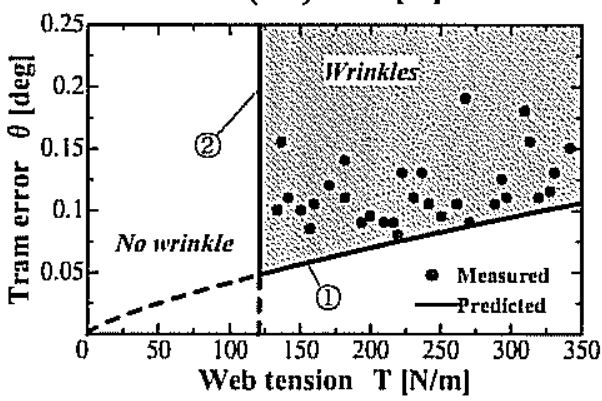

$(\mathrm{a}-3) \mathrm{L}=0.35[\mathrm{~m}]$

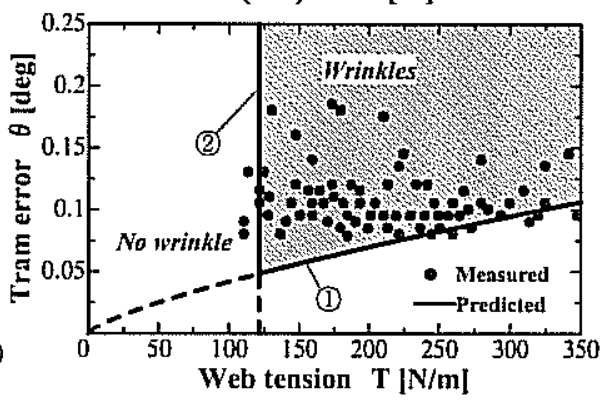

$(\mathrm{b}-3) \mathrm{L}=0.35[\mathrm{~m}]$

(i) $\mathrm{U}=1.0[\mathrm{~m} / \mathrm{s}]$

(ii) $\mathrm{U}=5.0[\mathrm{~m} / \mathrm{s}]$

Figure $12-$ Web wrinkling region for newsprint $\left(\mathrm{R}=0.04[\mathrm{~m}], \mathrm{a}=0.8[\mathrm{~m}], \mathrm{B}=60[\mathrm{deg}], \mathrm{k}=4.03 \mathrm{E}-15\left[\mathrm{~m}^{2}\right]\right)$

As predicted above, the applicability of present theoretical model was verified experimentally. Therefore, it may be possible to predict the generation of web wrinkling due to the misalignment of roller based on this model in many actual applications of roll to roll web transportation system. As one of examples of prediction, Figure 14 shows the 

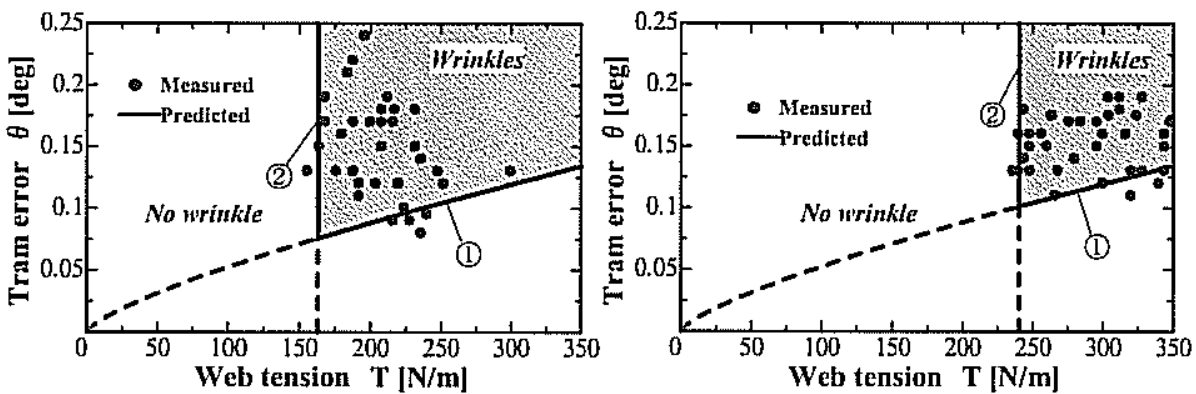

$(\mathrm{a}-1) \mathrm{L}=0.25[\mathrm{~m}]$
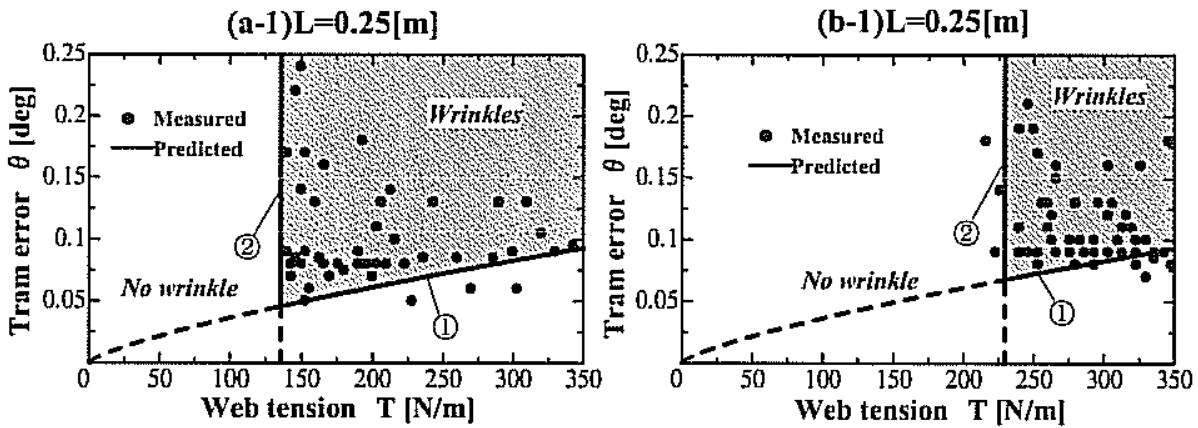

$(\mathrm{a}-2) \mathrm{L}=0.3[\mathrm{~m}]$

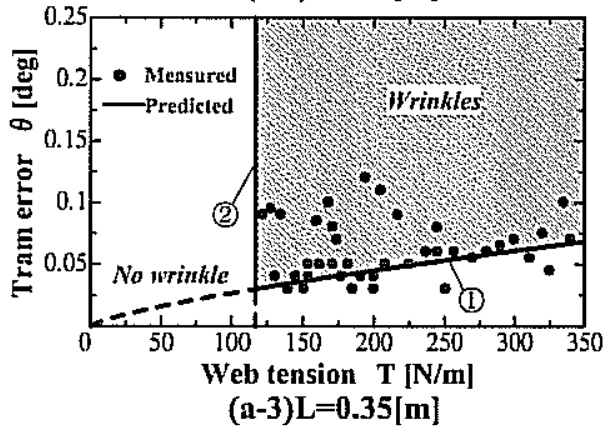

(i) $\mathrm{U}=\mathbf{1 . 0}[\mathrm{m} / \mathrm{s}]$

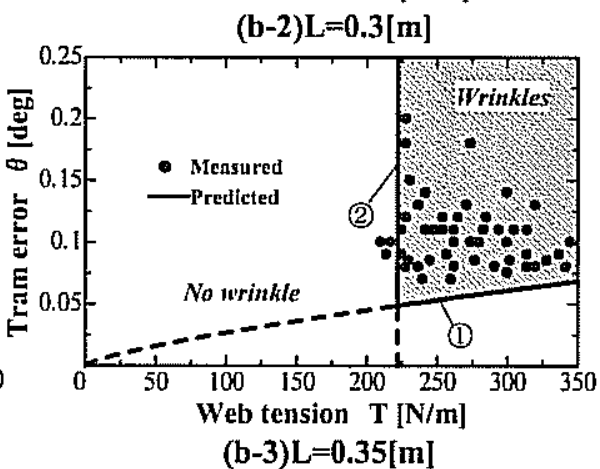

(ii) $\mathrm{U}=5.0[\mathrm{~m} / \mathrm{s}]$

Figure13 - Web wrinkling region for coated paper $\left(\mathrm{R}=0.04[\mathrm{~m}], \mathrm{a}=0.8[\mathrm{~m}], \mathrm{B}=60[\mathrm{deg}], \mathrm{k}=5.52 \mathrm{E}-17\left[\mathrm{~m}^{2}\right]\right)$

effect of nonuniformity in Young's modulus of webs on the generation of wrinkles. As can be seen in the figures, the nonuniformity in Young's modulus results in expanding the web wrinkling region. Thus, in the roll to roll transportation of nonuniform webs such as paper and liquid crystal films, it is needed to take into account such effects of nonuniformity of webs on the wrinkle generation. 


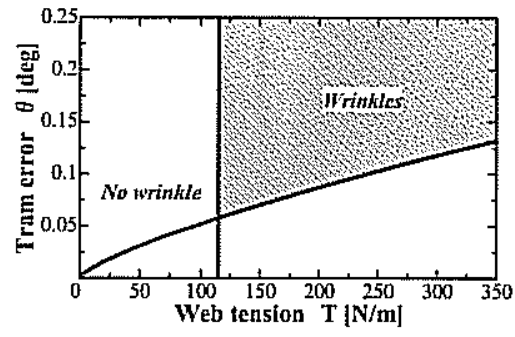

(i) $\left.\zeta_{\mathrm{I}}=1 / 4 \quad \mathrm{E}_{\mathbf{z}}=1.17[\mathrm{GPa}]\right)$

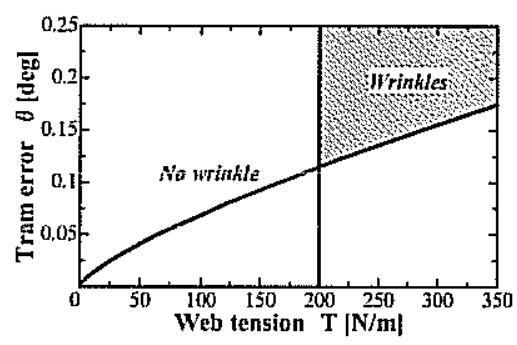

(iii) $\zeta_{1}=3 / 4 \quad E_{z}=3.50[\mathrm{GPa}]$ )

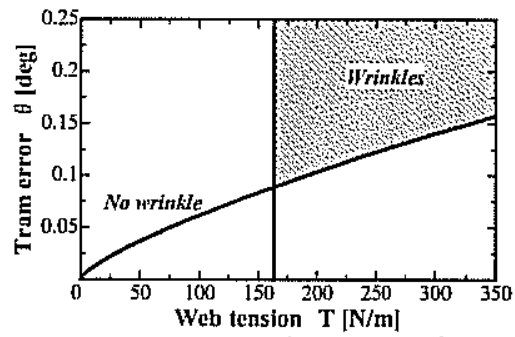

(ii) $\zeta_{1}=1 / 2 \quad E_{z}=2.33[G P a]$ )

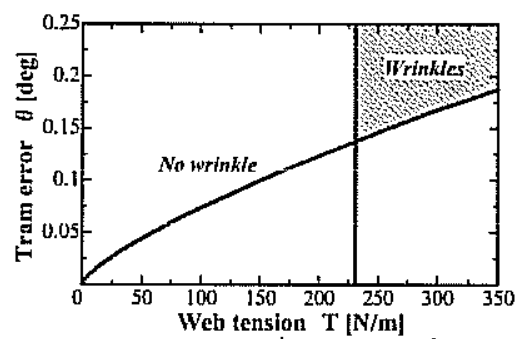

(iv) $\zeta_{1}=1 \quad \mathrm{E}_{\mathbf{z}}=4.66[\mathrm{GPa}]$ )

Figure14 - Variation of wrinkling region as a parameter of

Young's modulus of web in cross direction

$(\mathrm{U}=1[\mathrm{~m} / \mathrm{s}], \mathrm{R}=0.04[\mathrm{~m}], \mathrm{a}=0.8[\mathrm{~m}], \mathrm{B}=60[\mathrm{deg}], \mathrm{L}=0.3[\mathrm{~m}])$

\section{CONCLUSIONS}

The theoretical model for predicting the generation of web wrinkling due to the misalignment of roller was formulated based on the experimental observation for nonuniform webs with different Young's modulus in the machine and cross machine directions such as paper and liquid crystal films. The applicability of the model was verified by comparing the predicted results and the measured data obtained for various operation conditions.

\section{REFERENCES}

1. Gehlbach, L.S., Good, J.K., and Kedl, D.M., "Web Wrinkling Effects on Web Modeling," Proceedings of the 1987 American Controls Conference, 1987, pp. 2100 2102.

2. Gehlbach, L.S., Good, J.K., and Kedl, D.M., "Prediction of Share Wrinkles in Web Spans," TAPPI Journal, 1989, Vol.72, No. 8.

3. Shelton, J.J., and Reid, K.N., "Lateral Dynamics of a Real Moving Web," ASME Joumal of Dynamic Systems, Measurement and Control, 1971, Vol.93, No. 3, pp.180-186.

4. Shelton, J.J., and Reid, K.N., "Lateral Dynamics of an Idealized Moving Web," ASME Journal of Dynamic Systems, Measurement and Control, 1971, Vol.93, No. 3, pp.187-192.

5. Shelton, J.J., "Buckling of Webs from Lateral Compressive Forces," Proceedings of the Second International Web Handling Conference, Oklahoma State University, 
Stillwater, OK, June 6-9, 1993.

6. Good, J.K., Keld, D.M., and Shelton, J.J., "Shear Wrinkling in Isolated Spans," Proceedings of the Fourth International Web Handling Conference, Oklahoma State University, Stillwater, OK, June 1-4, 1997, pp. 462-479.

7. Swanson, R.P., "Testing and Analysis of Web Spreading and Anti-Wrinkle Devices," Proceedings of the Fourth International Web Handling Conference, Oklahoma State University, Stillwater, OK, June 1-4, 1997, pp.414-429.

8. Hashimoto, H., "Theoretical Modeling of Traction Characteristics Between Paperweb and Steel-Roller Based on the Contact Mechanics," Proceedings of the Eighth International Web Handling Conference, Oklahoma State University, Stillwater, OK, June 5-8, 2005.

9. Hashimoto, H., Okajima, M., and Numakura, T., "Effect of Permeability on Traction Characteristics Between Web and Roller for a Wide Range of Transportation Velocity," CD-ROM Proceedings of 2004 ASME/STLE Tribology International Conference, 2004.

10. Hashimoto, H., Theoretical and Experimental Investigations into Spacing Characteristics between Roller and Three Types of Webs with Different Permeabilities," CD-ROM Proceedings of 2004 ASME/STLE Tribology International Conference, 2004. 
Prediction Model of Paper-Web Wrinkling and Some Numerical Calculation Examples with Experimental Verifications
H. Hashimoto, Tokai

University, JAPAN

\begin{abstract}
Name \& Affiliation
Dave Roisum

Inc.

Name \& Affiliation

Hiromu Hashimoto

Tokai University

Name \& Affiliation

Bob Lucas

GL\&V USA, Inc.
\end{abstract}

Finishing Technologies, speeds than zero. How come?

\section{Question}

\section{Answer}

\section{Question}

The peak of the coefficient occurs at somewhat higher

It is very difficult to determine and must be determined case by case because the friction coefficient has a very complicated form. It depends not only on the web velocity and tension, but also surface characteristics.

One of the things we learned was when you have a closed loop such as you have the surface of the sheet becomes conditioned. The measurement of friction causes slippage which abrades the web surface and the surface asperities. We found that in our traction tests we had to constantly change the loop of web because the integrity of the surface of the sheet was being affected. 